\title{
Qualidade microbiológica da água de consumo humano e dos alimentos comercializados em lanchonete universitária
}

\author{
Tatiane FARIA ${ }^{1}$ \\ Ramon Alves de Oliveira PAULA ${ }^{2}$ \\ Jaqueline de Lima GERMANO ${ }^{2}$ \\ Josidel Conceição OLIVER ${ }^{2}$ \\ Bianca Gonçalves Vasconcelos de ÂLCANTARA ${ }^{2}$ \\ Camilla Ribeiro VIEIRA ${ }^{1}$ \\ Sandra Maria Oliveira Morais VEIGA ${ }^{3}$
}

${ }^{1}$ Graduanda em Nutrição, UNIFAL-MG (Universidade Federal de Alfenas)

${ }^{2}$ Graduandos em Farmácia, UNIFAL-MG

${ }^{3}$ Professora Doutora da UNIFAL-MG

Faculdade de Ciências Farmacêuticas / Faculdade de Nutrição

Universidade Federal de Alfenas

*tatianefaria_tf@yahoo.com.br

Recebido em: 30/10/2012 - Aprovado em: 28/12/2012 - Disponibilizado em: 30/12/2012

RESUMO: A produção de alimentos seguros é prática necessária e direito do consumidor, inclusive nas lanchonetes universitárias, espaço que atende uma variada clientela. Deste modo, é de fundamental importância avaliar a sanidade dos alimentos, prevenindo, assim, doenças de veiculação hídrica e alimentar. Este trabalho teve como objetivo avaliar a qualidade microbiológica da água e dos alimentos ofertados na lanchonete de uma universidade do sul de Minas Gerais. Para água de consumo humano, foram analisados os micro-organismos recomendados pela Portaria 2914 do Ministério da Saúde, sendo que todas as amostras apresentaram resultados satisfatórios. Para os alimentos, foram analisados os indicadores de contaminação sugeridos pela ANVISA (RDC 12/2001). Verificou-se a presença de fungos filamentosos e leveduras nas amostras de pão de queijo e suco de laranja. Além disso, foi confirmada a presença de Salmonella ssp na esfiha de carne e coxinha de frango. Sendo assim, análises confirmatórias foram realizadas, sendo que a Salmonella ssp continuou positiva. Além disso, na repetição das análises, constatou-se a presença significativa de estafilococos coagulase positiva em todos os alimentos. Os resultados encontrados mostram qualidade higiênico-sanitária insatisfatória de alguns alimentos analisados.

Palavras-chave: Microbiologia. Doenças Transmitidas por Alimentos. Lanchonete. Segurança alimentar. Controle higiênico-sanitário.

\section{Microbiological quality of drinking water and food sold in university cafeteria}

\begin{abstract}
Food production is safe and necessary practice consumer rights, including in university cafeterias, space that serves a diverse customers. It is therefore of fundamental importance to evaluate the health of food, thus preventing waterborne diseases and food. This study aimed to evaluate the microbiological quality of water and food offered in the cafeteria of a university in southern Minas Gerais. For water of human consumption, we analyzed the micro-organisms recommended by the 2914 Ordinance of the Ministry of Health, and all samples showed satisfactory results. For food, we analyzed the contamination indicators suggested by ANVISA (RDC 12/2001). There was the presence of yeasts and molds in samples of cheese bread and orange juice. In addition, we confirmed the presence of Salmonella ssp in esfiha meat and chicken drumstick. Thus, confirmatory analyzes were performed, and the continued positive Salmonella ssp. Moreover, the repeated analyzes, we found a significant presence of coagulase positive staphylococci in all foods. The results show satisfactory sanitary quality of some foods analyzed.
\end{abstract}

Keywords: Microbiology. Foodborne Diseases. Lunch. Food security. Hygiene and sanitary control. 


\section{INTRODUÇÃO}

O comércio de refeições prontas e lanches em universidades ocorrem rotineiramente em cantinas e, geralmente, estas não têm um controle da qualidade higiênico-sanitária da produção destes alimentos. Estes estabelecimentos, muitas vezes, não contam com as estruturas físicas adequadas e nem com a presença de um responsável técnico capacitado. Assim, pode apresentar um maior risco de veiculação de Doenças Transmitidas por Alimentos (DTAs) (KRAEMER et al., 2010).

Cerca de $60 \%$ das Doenças Transmitidas por Alimentos são de origem microbiológica e estão relacionadas diretamente à higiene pessoal inadequada dos manipuladores de alimentos, constituindo importantes problemas de saúde pública. (PLATA et al., 2007 apud BIONDO et al., 2011; FAÇANHA et al., 2003). A contaminação dos gêneros alimentícios pode ocorrer desde a sua origem ou em qualquer uma das fases, da produção ao consumo (ZANUSSI PROFESSIONAL, sd apud GONÇALVES, 2009).

$\mathrm{Na}$ maioria das vezes, os surtos de toxinfecção alimentar ocorrem em decorrência de falhas múltiplas observadas em serviços de alimentação, principalmente na questão da higiene. As principais falhas são: intervalo superior a duas horas entre o preparo e o consumo dos alimentos, inadequação no processo de refrigeração, manipuladores que são portadores sintomáticos ou assintomáticos de patologias, contaminação cruzada entre os alimentos, higienização incorreta dos alimentos, entre outros (GERMANO; GERMANO, 2007 apud DUTRA; ALVES, 2012;).

Segundo dados do Ministério da Saúde, no período de 1999 a 2008, verificou-se a notificação de 6.062 surtos de DTA, envolvendo 117.330 doentes, sendo que, cerca de $20 \%$ destas notificações foram oriundas de estabelecimentos de alimentação coletiva. No que se refere aos patógenos, os mais comuns foram a Salmonella ssp, Staphylococcus aureus, Bacillus cereus e o Clostridium perfringens (BRASIL, 2008).

Para as Doenças de Origem Alimentar (DOA), os sintomas podem variar desde um leve mal estar, cólicas, vômitos, febre, com duração de 1 a 3 dias, até casos mais graves, como aqueles causados por alguns sorotipos de Salmonela, que podem levar a hospitalização e evoluir para o óbito (VIEIRA et al., 2003). Gestantes, crianças, idosos, indivíduos imunodeprimidos e convalescentes são mais vulneráveis aos sintomas graves das DOA (OMS, 2002).

Os serviços de Alimentação e Nutrição devem fornecer uma refeição equilibrada nutricionalmente, além de apresentar um bom nível de sanidade e devem ser rigorosos em 
relação ao controle de qualidade dos alimentos servidos para assegurar a saúde do consumidor (POPOLIM, 2007; PINCHELLI et al., 2007 apud VERGARA; ALBUQUERQUE, 2010).

Para avaliar a qualidade microbiológica de alimentos, a RDC 12/2001 da Agência Nacional de Vigilância Sanitária apresenta os padrões legais vigentes para os diferentes microrganismos que indicam os riscos sanitários, bem como o potencial de deterioração dos diversos produtos alimentícios (BRASIL, 2001).

Segundo Almeida (1995), os alimentos produzidos por serviços de alimentação coletiva estão expostos a vários perigos microbiológicos, sendo que o principal fator desencadeante deste fato é a falta de conhecimento dos manipuladores. Assim, todas as pessoas que preparam, distribuem e/ou vendem alimentos devem ser capacitadas sobre as regras básicas de higiene e as Boas Práticas de Manipulação. A multiplicação de informações para a correta e segura manipulação de alimentos é de responsabilidade do nutricionista, de profissionais da saúde pública e tecnólogos da área (HAZELWOOD, 1998 apud MARTELO; LUZIA, 2010).

A Agência Nacional de Vigilância Sanitária (ANVISA) e as Vigilâncias Sanitárias Estaduais e Municipais são órgãos responsáveis pela definição, fiscalização e educação sobre os procedimentos adequados para a produção de alimentos, fundamentando-se nas Boas Práticas de Fabricação, conforme a RDC ANVISA ${ }^{\circ}$ 216/ 2004 (BRASIL, 2004). Esta resolução aplica-se aos serviços de alimentação, entre eles as cantinas institucionais que realizam algumas das atividades seguintes: preparação, manipulação, fracionamento, armazenamento, distribuição, transporte, exposição a venda e entrega de alimentos preparados ao consumo (RODRIGUES, 2006).

Por outro lado, a qualidade bacteriológica da água também é fator indispensável para a fabricação de alimentos seguros, assim as ações destinadas ao monitoramento da sua qualidade são indispensáveis em serviços de alimentação. Entretanto, ainda, há negligência por parte de muitos produtores de alimentos em relação à potabilidade da água (PORTO et al., 2011).

Para evitar ou minimizar a contaminação de alimentos durante sua produção e manuseio é de fundamental importância, a identificação dos pontos críticos para a contaminação microbiana e potencial aplicação de medidas de controle (GUIMEBRETIERE; NGUYEN-THE, 2003).

O estado de conservação e funcionamento de equipamentos e utensílios, bem como suas condições de limpeza tem influências sobre a qualidade final do alimento produzido. Tais inadequações podem ainda, favorecer a contaminação cruzada dos alimentos (GOMES, 2011). 
Considerando o exposto, este estudo objetivou avaliar a qualidade higiênicosanitária da água de abastecimento e dos alimentos de uma cantina universitária.

\section{MATERIAIS E MÉTODOS}

Este trabalho foi desenvolvido numa cantina de uma Universidade do Sul de Minas Gerais, no período de abril a julho de 2012. Esta cantina comercializa alimentos industrializados, preparados na própria unidade como salgados e sucos, além de produtos caseiros fornecidos por terceiros, tais como bolos e sanduíches. A clientela do estabelecimento é composta por discentes, docentes e servidores, além de pessoas que utilizam os serviços oferecidos pela instituição.

$\mathrm{O}$ estudo iniciou-se com a apresentação do projeto ao responsável pela cantina e aos funcionários. Em seguida, foi agendada a coleta das amostras, realizada em duas etapas, sendo a primeira no mês de maio e a segunda em junho de 2012.

\section{Análise de água e alimentos.}

Foram coletadas 08 amostras de alimentos e 06 amostras de água. O critério para definição das amostras de alimentos foi a identificação daqueles com maior saída. Os ensaios foram conduzidos no Laboratório de Microbiologia de Alimentos da Universidade Federal de Alfenas - MG.
A água foi coletada em três diferentes pontos sendo eles: filtro de barro, torneira da área de preparo e torneira externa (área de atendimento ao público). Foram realizados ensaios para Escherichia coli, Coliformes totais e bactérias heterotróficas aeróbias mesofílicas, além da determinação do pH e do Cloro, no momento da obtenção das amostras. A coleta e os ensaios realizados seguiram metodologias descritas por SILVA et al (2010) Foram coletadas e analisadas as seguintes preparações alimentícias: suco natural de laranja, coxinha de frango, esfiha de carne e pão de queijo. Os microrganismos pesquisados nos alimentos foram: Escherichia coli, Salmonella sp, Estafilococos aureus e fungos filamentosos e leveduras. A coleta e os ensaios realizados também obedeceram as metodologias descritas por SILVA et al (2010)

Análise de equipamentos e utensílios de cozinha.

Para análise dos equipamentos e utensílios, os microrganismos foram removidos das superfícies, consideradas higienizadas. Para tanto, empregou-se a técnica do swab, fundamentando-se em SILVA et al ( 2010) e ANDRADE (2008).

\section{Intervenção educativa}

Seguindo a proposta pesquisa em interface com a extensão, paralelamente, foi oferecido um curso de capacitação aos manipuladores de alimentos da cantina, com 
carga horária de 4 horas, amparado pela RDC no 216 (BRASIL, 2004), tendo por objetivo capacitar os manipuladores de alimentos sobre lavagem de mãos, processamento seguro, transporte, distribuição, armazenamento e comercialização de alimentos, dentre outros.

\section{RESULTADOS E DISCUSSÃO}

\section{Análise dos alimentos.}

De acordo com a RDC n. ${ }^{\circ} 12 / 2001$ da Agência Nacional de Vigilância Sanitária, estabelece-se para os alimentos um limite de quantificação máximo de $10^{2} \mathrm{NMP} / \mathrm{g}$ de Coliformes a $45^{\circ} \mathrm{C}$, de $10^{3} \mathrm{UFC} / \mathrm{g}$ de Estafilococos coagulase positiva e ausência de
Salmonella ssp em $25 \mathrm{~g}$ do alimento (BRASIL, 2001).

Quanto às análises microbiológicas de Coliformes a $45^{\circ} \mathrm{C}$, verificou-se uma quantificação inferior a 3,0NMP/g, de acordo com a Tabela 1. A ausência de Coliformes a $45^{\circ} \mathrm{C}$ indica condições higiênico-sanitárias satisfatórias dos manipuladores, dos equipamentos e do local de manipulação. Lemos et al. (2011), entretanto, observaram contagem de Coliformes a $45^{\circ} \mathrm{C}$ acima dos padrões especificados em uma amostra de coxinha no Litoral Catarinense; enquanto, Bonfanti et al. (2008) verificaram contagens inadequadas em amostras de suco de laranja na região do Médio Alto Uruguai, RS.

Tabela 1 - Resultados das análises microbiológicas realizadas em alguns alimentos comercializados em cantina universitária (primeira etapa).

\begin{tabular}{lcccc}
\hline \multicolumn{1}{c}{ Amostra } & Coliformes a 45 ${ }^{\circ} \mathbf{C}$ & $\begin{array}{c}\text { Fungos F. e } \\
\text { Leveduras }\end{array}$ & $\begin{array}{c}\text { Estafilococos } \\
\text { Coagulase positiva }\end{array}$ & $\begin{array}{c}\text { Salmonella } \text { sp. } \\
\text { Esfiha de Carne }\end{array}$ \\
Coxinha de Frango & $<3,0 \mathrm{NMP} / \mathrm{g}$ & $3,5 \times 10^{2} \mathrm{UFC} / \mathrm{g}$ & Ausente & Presente \\
Pão de Queijo & $<3,0 \mathrm{NMP} / \mathrm{g}$ & $8,5 \times 10^{2} \mathrm{UFC} / \mathrm{g}$ & Ausente & Presente \\
Suco de Laranja & $<3,0 \mathrm{NMP} / \mathrm{g}$ & $1,65 \times 10^{4} \mathrm{UFC} / \mathrm{g}$ & Ausente & Ausente \\
\hline
\end{tabular}

NMP/g: número mais provável por grama do produto; UFC/g: unidade formadora de colônia por grama do produto.

Com relação à quantificação de fungos filamentosos e leveduras, a RDC 12/2001 não traz limite para os alimentos analisados. Entretanto, para doces em pasta, purês, geléias e doces em calda, esta legislação apresenta como tolerância uma contagem de até $1,0 \times 10^{4} \mathrm{UFC} / \mathrm{g}$, assim é possível observar que a quantificação destes micro-organismos no pão de queijo e no suco de laranja apresentou-se ligeiramente elevada. Já na esfiha de carne e na coxinha de frango, as contagens se mostram reduzidas e dentro dos padrões desejados.

A presença de Estafilococos coagulase positiva em alimentos é preocupante, principalmente por estarem relacionados com 
surtos de intoxicação alimentar e com o controle higiênico-sanitário da manipulação dos alimentos SILVA et al. (2010). Inicialmente, os alimentos analisados não apresentaram contagens deste microorganismo. Porém, em uma segunda análise da coxinha de frango e da esfiha de carne, valores significativos foram obtidos. De acordo com a tabela 2, pode-se verificar que para a coxinha de frango, a contagem foi de $1,0 \times 10^{3} \mathrm{UFC} / \mathrm{g}$ e para a esfiha de carne,
2,0x1033FC/g, o que representa uma quantificação elevada para este último alimento, lembrando que na RDC 12 de 2001, consta que para amostras indicativas de alimentos prontos para o consumo a base de carnes, o limite máximo permitido para Estafilococos coagulase positiva é de $10^{3} \mathrm{UFC} / \mathrm{g}$. Gehlen et al. (2008) em seu estudo com coxinhas, em Passo Fundo, RS, encontrou $20 \%$ das amostras contaminadas com Sthaphylococcus aureus.

Tabela 2 - Resultados das análises microbiológicas realizadas em alguns alimentos comercializados em cantina universitária (segunda etapa).

\begin{tabular}{lccc}
\hline \multicolumn{1}{c}{ Amostra } & Coliformes a 45 ${ }^{\circ} \mathbf{C}$ & $\begin{array}{c}\text { Estafilococos Coagulase } \\
\text { positiva }\end{array}$ & Salmonella sp. \\
\hline Esfiha de Carne & $<3,0 \mathrm{NMP} / \mathrm{g}$ & Presente & Presente \\
Coxinha de Frango & $<3,0 \mathrm{NMP} / \mathrm{g}$ & Presente & Presente \\
Pão de Queijo & $<3,0 \mathrm{NMP} / \mathrm{g}$ & Ausente & Ausente \\
Suco de Laranja & $<3,0 \mathrm{NMP} / \mathrm{g}$ & Ausente & Ausente \\
\hline
\end{tabular}

NMP/g: número mais provável por grama do produto; UFC/g: unidade formadora de colônia por grama do produto.

Tabela 3 - Resultados das análises físico-químicas e microbiológicas de amostras de água potável colhidas em cantina universitária.

\begin{tabular}{cccccc}
\hline Local da coleta & $\mathbf{p H}$ & Cloro & $\begin{array}{c}\text { Bactérias } \\
\text { heterotróficas }\end{array}$ & $\begin{array}{c}\text { Coliformes a 35 } \\
\text { Coliformes a }\end{array}$ & $\begin{array}{c}{ }^{\circ} \mathbf{C} \\
{ }^{\circ} \mathbf{C}\end{array}$ \\
\hline Torneira Externa & 7,2 & 1 & $6 \mathrm{UFC} / \mathrm{mL}$ & Ausente & Ausente \\
Torneira da Área de preparo & 7,2 & 1,5 & $30 \mathrm{UFC} / \mathrm{mL}$ & Ausente & Ausente \\
Filtro & 6,8 & 0,4 & Ausente & Ausente & Ausente \\
\hline
\end{tabular}

UFC/mL: unidade formadora de colônia por mililitro.

A presença de Salmonella ssp em alimentos, torna-os impróprios para o consumo, pois ela é potencialmente capaz de causar toxinfecções alimentares (ARÇARI, 2011), sendo um dos principais agentes causadores de Doenças Transmitidas por
Alimentos em todo o mundo, ao lado de $S$. aureus, B. cereus e E. coli (OLIVEIRA, 2010). A tabela 1 demonstra que a esfiha de carne e a coxinha de frango apresentaram resultados positivos para a pesquisa deste micro-organismo. Análises confirmatórias 
foram realizadas e o resultado permaneceu positivo na coxinha e na esfiha. Gandra et al. (2011) encontraram Salmonella sp em 4 das suas 16 amostras de lanches, comercializadas em Umuarama, PR, contudo neste estudo estas foram relacionadas à presença de molhos a base de maionese nos lanches. Acredita-se que a contaminação pode estar relacionada com a carne bovina ou de frango, produtos alimentícios com alto potencial de contaminação por esse micro-organismo.

Os resultados apresentados na tabela 3 indicam que não houve a presença de Coliformes a $35^{\circ} \mathrm{C}$ e E. coli nas amostras de água analisadas, além disso, as contagens de bactérias heterotróficas, quando presentes, se mostraram satisfatórias.

Fortuna e Franco (2006), em seu trabalho em escolas do Rio de Janeiro, também obtiveram $100 \%$ das amostras com ausência de Coliformes a $35^{\circ} \mathrm{C}$ e E. coli. Já Rocha et al. (2010) verificaram a presença de Coliformes a $35^{\circ} \mathrm{C}$ e E. coli em $12 \%$ de suas amostras. A contaminação por coliformes pode ocorrer na captação da água do sistema público ou através das tubulações sujas e dos reservatórios. Assim, uma simples limpeza dos reservatórios com água sanitária e o correto fechamento do reservatório podem controlar esta contaminação.

A Portaria $n^{\circ} 2914$ rege os padrões de qualidade da água potável, e ela estabelece ausência de Coliformes a $35^{\circ} \mathrm{C}$, E. coli e contagens de bactérias heterotróficas inferiores a 500UFC/mL. Assim, somando-se as características microbiológicas e os parâmetros físico-químicos das amostras, a água analisada se mostra dentro dos padrões de potabilidade ao consumo (BRASIL, 2011).

Análises microbiológicas do suco e do pão de queijo indicam condições adequadas de consumo; do mesmo modo, as amostras de água analisadas mostraram-se $100 \%$ adequadas; entretanto, a esfiha e a coxinha encontraram-se contaminadas com patógenos preocupantes do ponto de vista higiênicosanitário.

\section{Análise de equipamentos e utensílios de cozinha.}

Os resultados apresentados na tabela 4 indicam que não houve a presença de Salmonella sp. nas superfícies analisadas, além disso, as contagens de bactérias aeróbios mesófilas e fungos filamentos e leveduras foram não significativas quando presentes.

A legislação brasileira não estabelece limites para contagem de micro-organismos em superfícies de processamento de alimentos. Considerando a recomendação de Andrade (2008), uma bancada está contaminada por micro-organismos mesófilos, fungos filamentosos e leveduras, quando contem valor igual ou superior a 2 $\mathrm{UFC} / \mathrm{cm}^{2}$. Desta forma pode-se concluir que a contaminação por Salmonella sp. não advém destas superfícies presentes na cozinha. Sugerindo que a contaminação por 
Salmonella sp. pode estar acontecendo por um manipulador portador assintomático da mesma, ou ainda pela carne contaminada.

Os manipuladores e portadores potenciais na veiculação de DTAs (GUIMARÃES, 2001; SHINOHARA et al., 2008).

assintomáticos de Salmonella sp. são fontes

Tabela 4 - Valores de UFC/ $\mathrm{cm}^{2}$ de microrganismos mesófilos, fungos filamentosos e leveduras e Salmonella sp. nas superfícies de equipamentos e utensílios da cozinha em cantina universitária.

\begin{tabular}{lllll}
\hline Micro-organismo em UFC/cm & Bancada de & Bandeja de & Estufa & Geladeira \\
& preparo & salgados & & \\
\hline Aeróbios Mesófilos & $<1,0$ & $<1,0$ & $<1,0$ & $<1,0$ \\
Fungos filamentosos e leveduras & $<1,0$ & $<1,0$ & $<1,0$ & $<1,0$ \\
Salmonella sp & ausente & ausente & ausente & ausente \\
\hline
\end{tabular}

Este trabalho é parte integrante do projeto Higiene dos Alimentos, que além das análises laboratoriais, oferecidas semestralmente, disponibiliza treinamentos para cantineiras e manipuladores de alimentos de cantina escolares e institucionais, conforme recomendado pela ANVISA, RDC n. 216 de 2004.

\section{CONCLUSÃO}

Este trabalho demonstrou a importância do monitoramento da qualidade microbiológica dos alimentos e da água, bem como da orientação dos manipuladores de alimentos, de forma a contribuir para implantação de técnicas higiênicas adequadas.

Os resultados encontrados mostram qualidade higienico-sanitária insatisfatória de alguns alimentos analisados.

Verificou-se ainda, a necessidade da implantação de uma legislação nacional com parâmetros para avaliar a qualidade microbiológica de superfícies e utensílios em estabelecimentos que comercializam alimentos.

\section{REFERÊNCIAS BIBLIOGRÁFICAS}

ALMEIDA, R. C. C. Análise de perigos e pontos críticos de controle no processamento de pratos cárneos para alimentação institucional. Campinas, 1995, 107p. Tese (Doutorado) - Faculdade de Engenharia de Alimentos, Universidade Estadual de Campinas.

ANDRADE, N. J. Higienização na indústria de alimentos; avaliação e controle da adesão e formação de biofilmes bacterianos. São Paulo: Varela, 2008. 412p..

ARÇARI, A. T. et al. Avaliação microbiológica da carne bovina comercializada em cinco supermercados de Vitória, ES. Revista Higiene Alimentar, São Paulo, v. 25, n. 202/203, p.138-144, nov./dez. 2011.

BIONDO, A. et al. Higiene dos manipuladores de alimentos de uma empresa 
de refeições coletivas em Caxias do Sul, RS. Revista Higiene Alimentar, São Paulo, v. 25, n. 198/199, p. 139-144, jul./ago. 2011.

BONFANTI, C. R. et al. Análise Microbiológica dos sucos de laranja produzidos e consumidos em alguns municípios da região do Médio Alto Uruguai, RS. Revista Higiene Alimentar, São Paulo, v. 22 , n. 160 , p. 42-47, jun. 2008.

BRASIL. Ministério da Saúde. Agência Nacional de Vigilância Sanitária. Resolução RDC $n^{\circ} 12$, de 2 de janeiro de 2001. Regulamento técnico sobre padrões microbiológicos para alimentos. Diário Oficial da república Federativa do Brasil, Brasília, DF, 2001.

BRASIL. Agência Nacional de Vigilância Sanitária - Ministério da Saúde. Secretaria de Vigilância Sanitária. Resolução RDC no 216, de 15 de setembro de 2004. Dispõe sobre o Regulamento Técnico de Boas Práticas para Serviços de Alimentação. Diário Oficial da União, Brasília, DF, 16 set. 2004.

BRASIL. Ministério da Saúde. Secretaria de Vigilância em Saúde. Coordenação de Vigilância das Doenças de Transmissão Hídrica e Alimentar. Análise Epidemiológica dos Surtos de Doenças Transmitidas Alimentos no Brasil, 2008. Disponível em: < http://portal.saude.gov.br/pdf>. Acesso em: 25 jul. 2012.

BRASIL. Portaria 2914, 12 de dezembro de 2011: Procedimentos de controle e de vigilância da qualidade da água para consumo humano e seu padrão de potabilidade. Ministério da Saúde, Brasília, 2011. 39 p.

DUTRA, J. S; ALVES, F. S. O conhecimento de manipuladores de alimentos sobre higiene: Um estudo de caso. Revista Higiene

Alimentar, São Paulo, v. 26, n. 204/205, p. 24-28, jan./fev. 2012.

FAÇANHA, S. H. F. et al. Treinamento para manipuladores de alimentos em escolas da rede municipal de ensino, da sede e distritos do município de Meruoca, Ceará: Relato de experiência. Higiene Alimentar, São Paulo, v. 17, n. 106, p. 30-34, 2003.
FORTUNA J.L.; FRANCO R.M.

Enumeração de coliformes totais e termotolerantes, em água de abastecimento de cozinhas de instituições de ensino público.

Revista Higiene Alimentar, São Paulo, v. 20, n. 147, p. 38-39, 2006.

GANDRA, E. A. et al. Condições higiênicosanitárias de lanches no comércio ambulante de alimentos de Umuarama, PR. Revista

Higiene Alimentar, São Paulo, v. 25, n. 2, p. 148-152, set. 2011.

GEHLEN, A. C. et al. Qualidade microbiológica de coxinhas e esfiras comercializadas em dez confeitarias da cidade de Pato Fundo, RS. Revista Higiene Alimentar, São Paulo, v. 22, n. 162, p. 96100, jun. 2008.

GOMES, N. A. A. A. Qualidade higiênicosanitária da alimentação oferecida em escolas publicas do estado de Goiás. Dissertação de mestrado - Faculdade de Nutrição, Universidade Federal de Goiás. Goiânia, 2011.

GONÇALVES, M. S. R. P. Higiene e segurança alimentar em cantinas hospitalares e satisfação dos utilizadores. 2009. 113f. Dissertação de mestrado Faculdade de medicina, Universidade de Coimbra, Coimbra, 2009.

GUIMARÃES, A.G. ; LEITE, C.C. ; TEIXEIRA, L. D. S. ; SANTíANNA, M. E. B. ; ASSIS, P.N. Detecção de Salmonella spp. em alimentos e manipuladores envolvidos em um surto de infecção alimentar. Revista Brasileira de Saúde e Produção Animal. v.2, n.1, 2001. Publicação Online da EMV - UFBA.

GUIMEBRETIERE, M.H; NGUYEN-THE, C. Sources of Bacillus cereus contamination in a pasteurized zucchini purée processing line, differentiated by to PCR-based methods. FEMS Microbiology Ecology; v.43, n. 2, p. 207-215, 2003.

KRAEMER, F. B. et al. Controle da qualidade em cantinas de uma Universidade pública: Melhoria contínua das práticas de fabricação. Revista Higiene Alimentar, São Paulo, v. 24, n. 183, p. 58-65, abr. 2010. 
LEMOS, M.P. et al. Qualidade higiênicosanitária de salgados e sucos servidos em lanchonetes de uma instituição de ensino superior do Litoral Catarinense. Revista

Higiene Alimentar, São Paulo, v. 25, n. 2, p. 142-147, set. 2011.

MARTELO, S.; LUZIA, D. M. M. Importância do Treinamento para manipuladores de alimentos em restaurante industrial. Revista Higiene Alimentar, v. 24, n.183, p. 66-69, abr. 2010.

OLIVEIRA, A. B. A. et al. Doenças transmitidas por alimentos, principais agentes etiológicos e aspectos gerais: uma revisão.

Revista HCPA, 30, p.279-285, 2010.

OMS - ORGANIZAÇÃO MUNDIAL DE SAÚDE. Información estadística sobre enfermedades transmitidas por los alimentos em Europa: peligros Microbiológicos y Quimicos. In Conferencia Paneuropea sobre calidad e inocuidad de los alimentos. Budapest, Hungria, 25-28 de fevereiro de 2002. Disponível em:

$<$ http://www.foodsafetyforum.org/paneuropea n/index_es.htm>. Acesso em: 26 jul. 2012.

PORTO, M. A. L.; OLIVEIRA, A. M.; FAI, A. E. C.; STAMFORD, T. L. M. Coliformes em água de abastecimento de lojas fast-food da Região Metropolitana de Recife (PE, Brasil). Revista Ciência e Saúde Coletiva, vol. 16, n. 5, Rio de Janeiro, maio 2011.

ROCHA, E. S. et al. Análise microbiológica da água de cozinhas e/ou cantinas das instituições de ensino do município de Teixeira de Freitas (BA). Revista Baiana Saúde Publica, v. 34, n. 3, p. 694-705 jul./set. 2010.

RODRIGUES, M. F. “Avaliação da aplicação da RDC 216/2004/ANVISA, nas unidades produtoras de refeição (UPRs), localizadas na quadra comercio local sul 402 do plano piloto, Brasília, DF”. 2006. 39f. Trabalho de Conclusão de curso (Especialização) - Centro de Excelência em Turismo, Universidade de Brasília, Brasília, 2006.

SHINOHARA, N. K. S.; BARROS, V. B.; JIMENEZ, S. M. C.; MACHADO, E. C. L.;
DUTRA, R. A. F.; LIMA FILHO, J. L. Salmonella spp., importante agente patogênico veiculado em alimentos. Revista Ciência e Saúde Coletiva, v.13, n.5, Rio de Janeiro Sept./Oct. 2008.

SILVA, N.; JUNQUEIRA, V. C. A.; SILVEIRA, N. F. A. TANIWAKI, M. H.; SANTOS R. F. S.; GOMES, R. A. R. Manual de métodos de análises microbiológicas de alimentos e água. $4^{\mathrm{a}} \mathrm{ed}$. São Paulo, Livraria Varela, 2010.

VERGARA, C. M. A. C; ALBUQUERQUE, M. B. Condições higiênico-sanitárias de restaurantes comerciais da cidade de Fortaleza, CE. Revista Higiene Alimentar, v. 25, n. 192/193, p. 29-34, jan./fev. 2010.

VIEIRA, C. R. N. Qualidade Microbiológica da merenda escolar servida nas escolas estaduais de Poços de Caldas, MG. Alfenas, 2003, 3.p Dissertação (Mestrado) - Escola de Farmácia e Odontologia de Alfenas.

\section{Agradecimentos:}

A Unifal-MG; ao PROEXT/MEC; aos professores e funcionários do Laboratório de Microbiologia de Alimentos da Unifal-MG; aos membros do Projeto de Extensão Higiene dos Alimentos pelo empenho na realização das atividades. 